\title{
Parents With Mental Illness: The Cycle of Intergenerational Mental Illness
}

\author{
Melanie Boursnell \\ University of Newcastle, Australia
}

\begin{abstract}
This article provides an insight into the under-explored lives of parents with mental illness. In particular, this article considers the experiences of parents with mental illness who grew up with parents who also had mental illness, or experienced issues related to violence, abuse and neglect during childhood. Due to the dearth of research in this area there is minimal insight into how parents experience mental illness and even less significance is placed on exploring how intergenerational mental illness and backgrounds of violence, abuse and neglect impact on parenthood. This qualitative study generates information about how intergenerational family mental illness, and other issues identified in the course of the study, affected the participants' experiences of being a parent.
\end{abstract}

Keywords: parents, mental illness, family, history, violence, abuse, intergenerational problems

Parenthood is a common life experience that offers people, including those with mental illness, an opportunity, among other things, to develop and enhance their capacity to deal with life challenges. Parenting can be a normalising life experience for people with mental illness. Parents with mental illness may, at times, be defined by their diagnosis, either as a patient or as a disabled person. This can result in a loss of opportunity to take on certain roles based on the social perception of their capacity to function (Mowbray, Oyserman, Bybee, MacFarlane, \& RuedaRiedlf, 2001). There are strong societal discourses that focus on the traditional family unit of a mother and father privately caring for their children that support entrenched beliefs about an innate parental capacity to care for children (Gilles, 2005). In western societies, mental illness is not a part of this 'ideal' (Davies \& Allen, 2007). As a consequence of societal ideologies, the role of parent is taken-for-granted, but frequently creates myriad issues for families who live with mental illness. At the outset it is important to delineate that this article is not generalising about all parents with mental illness and, second, that the discussion also pertains to the parents included in this research study (who had a diagnosis of both psychotic and nonpsychotic mental illnesses). Therefore, due to varying inherent resilience factors, not all children are affected to the same extent by parental mental illness and the comments made relate only to this cohort.
This research arose from providing parents with an opportunity to tell their stories about how they manage their mental illness and parental responsibilities on a daily basis (Boursnell, 2007). The parents in this study identified many concerns that are similar to those identified in other research and, in part, explain why there is limited data about the complex needs of families who live through mental illness A significant barrier to accessing services, related to possible risks for them and their children if they accessed help, was identified by parents. Accessing mental health services often means that parents will come under the surveillance of child protection systems (Bassett, Lampe, \& Lloyd, 1999; Bond \& Burns, 1998; Darlington \& Feeney, 2009; Nicholson \& Biebel, 2002). Furthermore, once in treatment, the perception of possible loss of child custody or visitation for nonadherence to treatment is not uncommon among parents treated in public mental health settings (Busch \& Redlich, 2007). However, an unexpected finding in this study was that a significant number of the parents felt that their parenting was impacted by their own parents' mental illnesses, as well as

ADDRESS FOR CORRESPONDENCE: Dr Melanie Boursnell, School of Social Science and Humanities, Faculty of Education and Arts, University of Newcastle, NSW 2308, Australia. E-mail: melanie.boursnell@newcastle.edu.au 
experiences of violence, abuse and neglect (VAN) in childhood. As this area is underresearched and underreported, the author felt that a specific article should be dedicated to opening up discussions about intergenerational transference of not only parental mental illness but also of VAN issues.

There continues to be debate about which mental health illnesses create a genetic predisposition (Pettit, Olino, Roberts, Seeley, \& Lewinsohn, 2008). Furthermore, there is debate about varying inherent resilience factors, as not all children are affected by parental mental illness to the same extent (Fraser \& Pakenham, 2009). The presence of resilience factors is known to minimise or prevent the adverse effects associated with the parental mental illness (Barnes \& Stein, 2000; Thomas \& Kalucy, 2003). In addition, there is significant disagreement about whether mental illness and other factors present in childhood, such as domestic violence (Kitzmann, Gaylord, Holt, \& Kenny, 2003), sexual abuse (McCloskey \& Bailey, 2000), use of alcohol and other drugs (Velleman Reuber, Klein, Templeton, \& Moesgen, 2008), can also create vulnerability in children and subsequent diagnosis of mental health issues (Chang, 2010).

The participants in this qualitative study suggested that learned behaviours as children who grew up in families with significant mental health issues led them to adopt dysfunctional behaviours as adults. This corresponds with other research that supports the idea that children who grow up with mental illness do not have the skills, knowledge or ability to adopt functional parenting practices and hence may repeat the cycles of intergenerational disadvantage (Maybery \& Reupert, 2006; Tandon, Cardeli, \& Luby, 2009) unless they are supported by services. While mental illness is not necessarily present with other factors - such as drug and alcohol use, domestic violence and childhood abuse - many of the parents in this study were coping with histories that included these issues, thus the connections between these issues will be explored.

\section{Literature Review}

A review of the literature was undertaken in order to explore the overlap in research between parental mental illness and intergenerational cycles of VAN. Firstly, there is a strong correlation between domestic violence and mental illness. This has been demonstrated in a number of studies (e.g., Campbell, 2002; Fischbach \& Herbert, 1997; Golding, 1999). Associations between domestic violence, anxiety and suicidal ideation have also been found (Roberts, Williams, Lawrence, \& Raphael, 1998; Taft, 2003). There is a body of research about women presenting with mental illness, both depressive and/or psychotic disorders, which indicates a significant portion of these women will have a history of some sort of abuse (Boursnell \& Prosser, 2010). Given that more women than men in Australia are parenting alone (Department of Families, Housing, Community Services and Indigenous
Affairs [FaHCSIA], 2010), more women than men will be diagnosed with mental illness (Australian Institute of Health and Welfare [AIHW], 2010), and more women than men are victims of domestic violence (Carrington \& Phillips, 2003), research must bring together all of these different areas to create a deeper understanding of these issues and the potential impacts on parenting.

Chronically mentally ill women seem to experience higher rates of abuse and more types of abuse than the general population (Sirotich, 2008). Fischbach and Herbert (1997) found that the incidence of depression is also increased in people who have suffered domestic violence. However, there appears to be a lack of agreement on whether mental illness causes violent relationships or whether the domestic violence may cause mental illness, with neither being a definitive cause. The research highlights the contention surrounding domestic violence as a risk factor for psychiatric disorders in women but does not focus on their roles as parents. Despite this oversight, other research such as that by Golding (1999) adds to the argument that women will exhibit higher rates of depression and posttraumatic stress disorder if they have a history of domestic violence and are three times more likely to be diagnosed with depression. It is not surprising, given that most women will become mothers, that this should be an area of exploration for research. It is also clear that while mental illness can impact on parenting, though not necessarily in a violent way (Kyoung Kahng, Oyserman, Bybee, \& Mowbray, 2008), it could be lack of parental involvement during childhood that causes attachment issues that are subsequently repeated in parenting roles (Pretis \& Dimova, 2008).

It is well known (see, e.g., Ehrensaft, Moffitt, \& Capsi, 2006) that being in an abusive relationship does not solely cause mental illness, but that mental illness may be exacerbated by additional stressors resulting in mental ill health (Price-Robertson, Smart, \& Bromfield, 2010). For those predisposed to mental illness, such situations may initiate serious concerns about mental illness. Furthermore, being a parent within such relationships could further elevate concerns, both for the parent and child (Behrens, 2010). It is possible that, when extending the argument to parents with mental illness, both men and women with a psychiatric disorder may be at increased risk of being in violent relationships or continuing their cycle of violence, abuse and neglect into their relationships with their children (Connell \& Goodman, 2002). Ehrensaft et al. (2006) support this proposal; women may experience increased psychiatric disorders/symptoms while in an abusive relationship and this will naturally impact heavily on their parenting capacity.

The literature is not, however, conclusive about whether mental health problems are outcomes of abuse rather than precursors. Ellsberg, Henrica, Jansen, Heise, Watts and Garcia-Moreno (2008) advise that myriad con- 
tributory factors may create parental vulnerability. Subsequently, parents with mental illness who have endured the effects of adverse childhood experiences such as VAN, poor interpersonal functioning and lack of schooling may be affected by low self-esteem (Dixon, Browne, \& Hamilton-Giachritis, 2005; Sidebotham et al., 2006). It is proposed that this poor sense of self may exacerbate a predisposition to mental illness. However, knowledge about the precursors or other factors that may impact on parenting capacity is hampered by the dearth of research. While research is addressing the presence of comorbid disorders in adults with mental illness, such as drug and alcohol use (Taylor, Toner, Velleman, \& Templeton, 2008), and connections are also being made with families who live with such issues and experience domestic violence (Velleman et al., 2008) and/or childhood sexual abuse (Spataro, Mullen, Burgess, Wells, \& Moss, 2004; Macy, Giattina, Parish, \& Crosby, 2010), there is little research on parents with mental illness and their experiences when considered in tandem with these issues.

In addition, the published literature on the intergenerational occurrence of mental illness provides numerous reasons of how this also impacts on family life (PriceRobertson et al., 2010). Hence, the body of mental health research focusing on current parental factors includes reference to the inherited genetic make-up of the child (Manning \& Gregoire, 2009; Chang, 2010), the home environment, effective parenting strategies and supervision (Kahng, Oyserman, Bybee, \& Mowbray, 2008) and the risk of direct exposure to the parental mental illness itself (Maybery \& Reupert, 2006). Furthermore, other factors may impact on the child's development, for example socioeconomic disadvantage (Benjet, Azar, \& KuerstenHogan, 2003) and marital conflict (Ramchandani \& Stein, 2003). Marital conflict, although explicated, may include domestic violence and other patterns of violence, abuse and neglect that may affect the parent and child's relationship.

Existing research into the concerns of parents with mental illness continues to be limited with much of the research focusing on the children rather than the parents' stories. The research available could be classified into: outcomes for children of parents with a mental illness (Alakus, Conwell, Gilbert, Buist, \& Castle, 2007; Maybery, Ling, Szakacs, \& Reupert, 2005); effects of mental illness (Ramchandani \& Stein, 2005); and child protection issues (Berger, 2005; Cousins, 2004; De Bellis, et al., 2001; Cleaver, Unell, \& Aldgate, 1999; Hetherington, Baistow, Katz, Mesie, \& Trowell, 2002; Nicholson \& Denevey, 2009; Trocme \& Wolfe, 2001). Much of the mental health research concerns how parental mental illness affects attachment between the parent and child (Newman \& Mares, 2007). Such impacts are significantly detrimental to children (Reid, 2005). The literature also focuses on the importance of a nurturing environment as a protective factor to those genetically predisposed to mental disorder, however the genetic structure of the transmission is not yet fully understood (Curtis, 2008).

Lastly, after significant review of the research, it is clear there is a dearth of research that brings together both areas of VAN, mental illness and parenthood. This is despite many families experiencing mental illness and who may also endure isolating and marginalising conditions already identified in this article. Only estimates are provided with regard to the number of families who may be affected by these factors as there are inconsistent data collection systems and inadequate connections between services (Hetherington et al., 2002). Hetherington notes: ' ... there are some figures about mentally ill adults who are parents. There are some figures about children in need of protection who have mentally ill parents. But these figures do not join up' (2002, p. 183). While a specific finding in the literature has been that mental health disorders at 18 years may predict partner violence at ages 24-26 years, there is no mention of how this may affect mental health and how this may subsequently impact on parenthood. This fact is important though, as many parents enter parenthood in their mid-twenties and, as a consequence, the issues and stressors of their background may be brought to the surface and present difficulties.

Generally, it may be argued that the social sciences have neglected this field and more research with children of parents with mental illness is needed to develop opportunities for preventative responses that can counter embedded stigmatised attitudes (Sartorius \& Henderson, 1992). Indeed, our national mental health policies and agendas support the need for increased research to be undertaken to assist service developments and, consequently, affect generational change. It is interesting, however, that a new body of research is emerging that is identifying and evaluating emerging programs that may support development of parental capacity-building in disadvantaged families (for instance, Fudge \& Robinson, 2009; Nicholson \& Denevey, 2009; Reupert \& Maybery, 2009). If significant progress is to be made in work with these marginalised families to prevent these intergenerational cycles, then significant understanding must be developed about their lives - this article opens up the debates.

\section{Methods}

This article discusses 23 parents who participated in an empirical study about their experiences of parenthood and mental illness in New South Wales, Australia. Parents were not asked about their diagnosis or other health issues, nor had I set out to delve into the family backgrounds of the parents. However, when talking about their lives, some of the parents provided their stories about intergenerational mental illness or stories that featured abuse. This issue deserves discussion as there is little written on the complexities of the lives of parents with 
mental illness, and even less that addresses the issues under discussion in this article.

The qualitative research process explored the personal narratives and accounts of the parents with mental illness. This methodology allowed parents to talk about their lives in their own words. Once ethical approval was granted, the selection of participants commenced. Due to the sensitive nature of research about mental illness, processes were designed to support the data collection while also protecting the vulnerability of participants. This was undertaken to ensure that the rights and interests of the parents who participated in the research were adequately protected. All parents had good support networks and their support agencies indicated that they were well enough to participate in the interviews. Issues of both confidentiality and anonymity were also considered in study design, such as the use of pseudonyms.

\section{Participants}

Participants were recruited through nongovernment mental health service providers from clients who were parents of children aged 0-18 years of age. While experience of public health services was not part of the inclusion criteria, all of the parents had experience of government mental health services. The research did not discriminate between mothers and fathers, but rather looked at the issues raised about parenthood and represents the views of parents with mental illness.

\section{Data Collection}

Data was collected during individual interviews with parents, lasting on average one hour. Parents were provided with information about the study by their mental health organisation and, if interested and permission was provided, they were contacted by the researcher for an interview. The interviews followed a loose thematic guide, but were largely fluid in order to allow the parents to explain their experiences in their own words. This methodology allowed for deep discussion and allowed exploration of many facets of their lives. With consent of the participants, interviews were tape recorded and no identifying data was collected.

\section{Data Analysis}

After the interviews the tapes were transcribed and verbatim transcripts were produced. Concurrent with this process, notes were taken by the researcher (Grbich, 1999). Immediately after the interviews these notes were collated to allow for a comprehensive picture of the parents' lives to be developed. The transcripts were analysed using narrative analysis. They were subjected to thematic coding and it was during this process that decisions were made about themes arising from the data (Lawler, 2002). The data was subjected to analytical coding where interpretation assisted in the expansion of understanding of the meaning and processes surrounding the issues discussed
(Silverman, 1993). This process was ongoing and involved the researcher referring to the literature in this area in order to develop understanding about the themes that were developing. These themes are presented in the next section of this article.

\section{Findings: Intergenerational Reflections on Mental Illness}

A number of caveats should be noted as the findings of this study are presented. The interviews are based on the recall of 23 parents with mental illness and their daily lives as remembered by them. Some of the stories were recent while others were not. It is possible that recall bias and discrepancies may be present which, in turn, could impact on the data in terms of accuracy and reliability (Pescosolido \& Wright, 2004. The generalisability of the findings should be considered with caution (Payne \& Williams, 2005). For instance, the experiences of individuals in other parts of Australia may be very different to the accounts from the parents interviewed in this study, but the accounts resonate with one another and with other qualitative studies (Kai \& Crosland, 2001; Lester et al., 2005).

\section{Repeating the Cycle}

It became evident very early in this study that most of the parents had backgrounds not only of mental ill health within their families, but also of violence, abuse and neglect issues, including drug and alcohol use. This links to issues of carers and children as potential carers of their parents, similar to recent research by Foster (2005). One parent explains how this role had affected her life as she grew up:

She [participant's mother] has got lots of anxiety problems herself, and that kind of thing ... she has got this real thing that everything is inherited. I just couldn't believe how much I loved him [participant's son] and I just didn't want to hurt him and I didn't want to be the reason why he had a bad life. (Mother of one)

Seventeen parents $(70 \%)$ had a family history of mental illness through parents, grandparents, siblings or other close relatives (cousins, aunties and uncles). Consequently, the propensity for mental ill health within this community sample of family connections was significant. This adds weight to the arguments that support the intergenerational transference of mental illness (Birtchnell, 1974; Repetti, Taylor, \& Seeman, 2002), but also to biopsychosocial arguments about mental illness and children's environments having significant effects on developments. For a few parents, their history of abuse not only occurred during childhood, but also continued into adult relationships (for example, domestic violence, and drug and alcohol use). Their experiences covered physical, emotional, sexual and psychological abuse. A number of parents felt that their history of abuse was interrelated 
with the development of their mental health issues. An example of the impact of intergenerational mental illness can be seen in one reflection:

One thing I was worried about before I had the two children was that I wouldn't pass the illness on. I actually went to see a female doctor who specialised in men's things. I asked her to speak to someone about punching numbers to find out about passing it on because I was diagnosed at the time. They said the chances were probably fairly high, like one in 200,000, or that sort of thing. It was enough to make me concerned. (Father of two)

This excerpt shows a deep insight into the effects of living with a parent with mental illness, from the perspective of a parent with mental illness. One of the issues raised relates to the impact of the lack of explanation about mental illness on children. Similar thoughts were echoed by another parent who had also felt this lack of access to information:

It's frightening though, you know, wanting to hide and needing a security, because I have got three kids and they think, yeah, brave man ... just seeing that everything that you are doing with the kids, you are like a mirror and before that, you are just a reflection of you in all three of them ... I am passionate, and my old man was, too. I remember as a kid watching this Skippy or some movie - you know, like, Skippy fell off a cliff, you know, and the old man would be bawling his eyes out. I was, like, what is this shit, what is wrong with him? And it's heavy, you know, but I am the same. I never understood the oldies fighting and all the other things around me, yeah, yeah, it's always just like that. And then all of a sudden the old man just died, and it was like, bang, straight into the big wide world no answers. (Father of three)

The parents talked about their family backgrounds and experiences of abuse during childhood. These conversations included reflections on living with parents or partners who abused alcohol and other drugs:

My brother escaped by drugs and alcohol and he's been missing for 20 years now and he would be 42 . But I escaped by being a good student and then getting 'A's and topping my class and studying. I escaped that way until I married that girl's father and he was abusive. And then I started drinking and I would drink everything until it didn't hurt anymore. (Mother of two)

The conversations also included reflections on partners who were psychologically violent towards them or their children:

I never dreamt that people could do that to their own child, but he has schizophrenia - although you cannot blame what he's done on mental illness. I reckon we are going to have to be careful with him [her son] because of the trauma - trauma is really mental illness. I have a hard time with my son because he has been hurt badly by his father and he just yearns for a lovely male figure. His father is very self-centred, he locked him up in the house and went out at night and made him watch scary movies. That is the trigger [raising your voice]; every time his father raised his voice he knew that something was always going to happen to him. (Mother of one)

It appears from the experiences of this group of parents that if parents have repressed issues from their childhood, then they will have significant issues later in life when these resurface. While there continues to be limited evidence to support intergenerational transmission of mental illness (Oyserman, Mowbray, Allen-Meares, \& Firminger, 2000; Repetti, Taylor, \& Seeman, 2002), some parents in this study were determined that the lives of their children would not be affected by their mental illness:

My mum was great, but she was also very scared for me to go into hospital because she went into hospital and it was bad. I just remember her crying quite a bit, sitting at home crying, and just not understanding that it was depression at the time. A few years later she told us that she had depression. But I still didn't really understand it, you know, the ramifications of it all, and what she was going through ... We never really talked about it, but from an early age, I knew that she had depression, but I didn't ask a lot of questions. (Mother of two)

One of the arguments that this data presents is that the issue may not be the intergenerational transmission of symptoms but rather learned behaviours, self-fulfilling prophecies and expectations that children will become mentally ill.

The generations pass it on, my dad's brother is schizophrenic, and my grandfather was different, but towards the end of his life, he came off his medication and he was quite normal, you know. I never knew him to be any different, but dad said when they grew up he was very different, he was quiet and withdrawn. But I get like that, too, you know when I am going through an episode and I put the walls up around me so that no-one can hurt. (Father of three)

For many parents there was significant fear about mental illness, this suggests the need to increase opportunities for parents to participate in education (Ackerson, 2003; Bunting, 2004; Craig, 2004). Perhaps greater support in the provision of information, education and literature about mental illness for children and families would, in part, reduce these anxieties (Devlin \& O'Brien, 1999). As some of the vignettes have shown, some parents were profoundly affected by growing up with parents or family members with mental illness. The consequence of this experience was that they are now vigilant in attempting to break the cycle of intergenerational transmission of mental illness:

I look at my girls and they are quite happy, but I am always looking at them to see if they are behaving differ- 
ently or anything like that, because I am aware of the triggers and stuff like that. (Mother of two)

This overanalysis of their children also included providing information to their children about mental illness and avoiding disruptions in parenthood created by institutional care: 'Mental illness needs to be part of their lives, she knew about it. It's not just about the parents; it's also about the kids' (Father of two).

This father was perhaps more sensitive to the effects of mental illness on children. A concern was raised that parents' lack of recognition of the effects of their illness on their children creates fear for the children, especially if they do not understand what is happening to their parents. Parents wishing to break the cycle of mental illness within their families went to great lengths to make changes in their families, in spite of their own memories often being very active: 'I kept having flashbacks from when I was younger and I thought the ground was breaking up around me' (Mother of two).

The strategies that were discussed in the interviews showed parents' resilience and attempts to make plans for days when they felt sick, including adhering to medication regimes in order to be around to participate in his children's lives.

\section{Breaking the Cycle}

Parents talked about wanting to be open about their mental illness with their children and providing them with answers as to what might happen if their illness became worse and they needed to have inpatient care. Indeed, this research is supported by similar findings by Maybery, Ling, Szakacs and Reupert (2005) who found that educating children about mental illness provided them with the knowledge and empowerment to deal with the issue. Only a few parents had actually talked to their children about mental illness because their children were older and better able to understand what it meant. Other parents had younger children and so had not reached a point where they felt that it was important for the children to know about their illness or their family background. One parent, the child of a parent with mental illness herself, had been talking to her daughter about mental illness since she was young:

I think I have managed quite well even though I have been depressed. I speak to her like an adult but appropriate to her age, and I explain things in a way that she can understand. There were times when she didn't understand and she would want to have it explained. I explained it and she still didn't get it. She would get stroppy even if I explained it bluntly. I would say, see, you are not going to be able to understand till next year, and we will go through it next year and see if you understand or we will go through it again in six weeks if you understand then. And the she accepted that and she ran off to play. (Mother of one)
There are few options available to support families to build their skills and resilience in living with the effects of mental illness. However, in an attempt to break the intergenerational patterns within families, some parents had sought professional support and attended programs for children of parents with mental illness:

They understand, like, we have explained it to them we have been to counsellors. So they understand, but they still find it hard. Counselling really helped. [Talking about his elder daughter] she finds it hard because she knew what I was like before and she can see me now. (Father of two)

Other parents, though, had found mutual support in their nongovernment organisations or had attended peer support groups where they met people who had similar experiences to themselves. For some parents these forums and discussions provided them with suggestions, and sometimes skills, which they felt could assist them in defying the transmission of symptoms between parent and child. However, without doubt, most parents were determined to break the cycle, if at all possible. This thought harmonises with Devlin and O'Brien (1999) who also found that, if supported, families can prevent the transference to mental illness to subsequent generations.

\section{Talking About Family}

The difference for most parents came with being open about their issues and being able to talk about how mental illness and family histories had affected their lives. Sometimes knowing that a family had a history of mental illness and VAN means that services can anticipate support needs, but parents did not always report that this was positive:

Because of the abuse in my family, the family was a risk, and so I was a risk to my child even before he was born. They had already decided and they had this counsellor speaking to me whenever I went to the hospital. My mum had been in hospital and everything, you know, so ... And it was the same hospital, and they knew about it [history of abuse]. It's awful, yeah, but you get used to it. (Mother of two)

Interestingly, none of the parents had ever discussed their parental capacity with mental health workers. Discussions with mental health workers about their families had not included assessing whether or not they had abuse and neglect in their backgrounds. For instance:

Throughout my whole pregnancy, and when I went back for my visits, no-one ever mentioned it. And then when I left hospital, one of the nurses kind of said to me that, you know, you are more susceptible to getting sick, so make sure you look after yourself ... They never asked me if I was a parent, but [if I had told them] social services would have taken her [her daughter]. (Mother of one) 
This lack of effective assessment is supported in previous research, such as that by Dixon et al. (2005), and perhaps also reflects the constraints of developing family-sensitive practice into clinical services (Furlong, 2001). Many of the parents reflected that their participation in the research interview was the first time that they had the opportunity to tell their stories. However, mental illness and other family issues impact heavily on the parents, creating complexities in their lives; and they also identified the risk of disclosing their backgrounds as setting a precedent for their own children.

\section{Discussion}

The limited research on adult children of parents with mental illness means there is inconclusive evidence to support the focus on parents with mental illness as a constant risk to their children. It appears from this research that children, like their parents, are resilient and can be good parents if provided with adequate support.

Successful outcomes depend on the appropriate kind of support to parents being provided in a nonjudgmental and nonthreatening way. If parents feel that their parenthood will be put under scrutiny they are less likely to access services, even when they need help. The family history of mental illness creates issues for some families and, as Wright and Owen (2001) suggest, some mothers are more likely to be diagnosed with a mental illness. A reason for this is provided by Cowling, Luk, Mileshkin and Birleson (2004) who propose that children of parents with mental illness are at greater risk of developing a psychological disorder than children whose parents do not have mental illness. As such, children who grow up with parents with mental illness may also suffer from other comorbid factors which, it is argued, also impact on children's chances of normal development (Cowling, Edan, Cuff, Armitage, \& Herszberg, 2006). The parents in this research reject much of this positioning, focusing instead on the need for adequate support, including education about mental illness. Issues of risk related to parents with mental illness are often used to justify concerns or allegations of risk to children, but these issues were not apparent or widespread in this group of parents. This could be due to the demographics of the research participants who all had a good standard of education and were drawn from community sources and possessed different characteristics from those people who access statutory mental health services.

Whether there is a genetic predisposition to mental illness or abuse continues to be debated (Manning \& Gregoire, 2006), though it is agreed that there may be causative significance and the focus of research should be on what can be done to prevent or reduce impact of such illness on an individual's life. Accounts by parents in this study suggested the possibility of learned behaviours, which are often labelled as social transference of mental illness. Behaviours associated with mental illness or abuse may be accepted as normal by the child. For instance, Foster (2005) suggests that some concerns about children's development can be attributed to their parents' mental illness. However, the intergenerational transmission continues to be debated and it is possible to hypothesise that behaviours are learned, due to the systemic neglect of these families. What is problematic is the lack of intervention and support available that could lower these statistics.

The dominant discourse remains focused on mental ill health presenting barriers to effective parenting. For instance, Cooklin (2006) suggests, 'There may be significant under-reporting of abuse by children of mentally ill parents, even among those - relatively few - who are given an opportunity to talk about their experiences' ( $p$. 266). There was direct evidence of failure to disclose abuse in this study. Instead, the strong focus on positive parenting was commensurate with other studies, such as that of Nicholson et al. (2007) who argued for more positive aspects of parenting to be discussed. Furthermore, in accordance with other studies (for example, Pretis \& Dimova, 2008) it appears that if parents are supported adequately it is possible to intervene and break these intergenerational patterns of mental illness and abuse.

\section{Concluding Remarks}

The narratives of the parents presented in this article provided a picture of mental illness, parenting and how it is affected by intergenerational VAN issues. The parents identified that the provision of services, including education for families like them, is important in order that they be adequately equipped to deal with the challenges of mental illness and parenthood. Access to support is critical given the high incidence of mental illness, domestic violence and abuse in society that affects the many families living in similar circumstances to those identified in this article. For those who are able to identify with the voices of the parents in this article it is imperative that we consider how to effectively support them.

Findings from this study may assist development and refinement of interventions and could provide the groundwork for further research, including replication of this study. It is important that we continue to build the evidence base for parents with serious mental illnesses and their families, in particular when intergenerational issues are problematic (Nicholson, Albert, Gershenson, Williams, \& Biebel, 2009).

The parents participating in this research study provided a window of opportunity through which improved understanding could be developed. They continue to parent while living with both current and historical experiences of mental illness, violence, abuse and neglect issues. Despite the challenges presented, many families live life well and the children of these parents often succeed in spite of the setbacks outlined in this article. It does appear, 
however, that the success of these families is directly related to the number of strengths and challenges within the family; the greater the number of strengths and the smaller the number of challenges, the greater the likelihood of the family coping. What is needed is more research in order that services for families and children can be improved and, as a result, increase the opportunities for children to succeed and avoid repeating patterns within their families.

\section{Acknowledgments}

I would like to thank the two anonymous reviewers for their extremely insightful comments on a different version of my manuscript.

\section{References}

Ackerson, B.J. (2003). Parents with serious and persistent mental illness: Issues in assessment and services. Social Work, 48(2), 187-195.

Alakus, C., Conwell, R., Gilbert, M., Buist, A., \& Castle, D. (2007). The needs of parents with a mental illness who have young children: An Australian perspective on service delivery options. International Journal of Social Psychiatry, 53(4), 333-339.

Australian Institute of Health and Welfare. (2010). Australia's Health Wrap up 2010. Retrieved November 8, 2010, from http://www.aihw.gov.au/access/201010/feature/aus_health 10.cfm

Barnes, J., \& Stein, A. (2000). The effects of psychiatric and physical illness on children. In M.G. Gelder, J.J. LopesIbor \& N.C. Andreasen (Eds.), The New Oxford Textbook of Psychiatry. Oxford, UK: Oxford University Press.

Bassett, H., Lampe, J., \& Lloyd, C. (1999). Parenting: Experiences and feeling of parents with mental illness. Journal of Mental Health, 8(6), 597-604.

Behrens, J. (2010). Family violence and its relevance beyond safety: Some reflections on the Chisholm Report. Family Law Review, 1(1), 31-39.

Benjet, C., Azar, S.T., \& Kuersten-Hogan, R. (2003). Evaluating the parental fitness of psychiatrically diagnosed individuals: Advocating a functional-contextual analysis of parenting. Journal of Family Psychology, 17, 238-251.

Berger, L.M. (2005). Income, family characteristics, and physical violence toward children. Child Abuse and Neglect, 29, 107-33.

Birtchnell, J. (1974). Is there a scientifically acceptable alternative to the epidemiological study of familial factors in mental illness? Social Science \& Medicine, 8(6), 335-350.

Bond, L.A., \& Burns, C. E. (1998). Investing in parents' development as an investment in primary prevention. Journal of Mental Health, 7(5), 493-503.

Boursnell, M.S. (2007). The silent parent: Developing knowledge about experiences of parents with mental illness. Child Care in Practice, 13(3), 251-260.
Boursnell M.S., \& Prosser, S. (2010). Increasing identification of domestic violence in emergency departments: A collaborative contribution to increasing the quality of practice of emergency nurses. Contemporary Nurse, 35(1), 25-46.

Bunting, L. (2004). Parenting programmes: The best available evidence. Child Care in Practice, 10, 327-343.

Busch, A., \& Redlich, A.D. (2007). Patients' perception of possible child custody or visitation loss for non adherence to psychiatric treatment. Psychiatric Services, 58(7), 999.

Campbell, J.C. (2002). Health consequences of intimate partner violence. The Lancet, 359, 1331-1336.

Carrington, K., \& Phillips, J. (2003). Domestic violence in Australia: An overview of the issues. (E-Brief: Online Only Social Policy Group. Issued 7 August 2003, updated by Janet Phillips, September 2006). Retrieved November 8, 2010, from www.aph.gov.au/library/intguide/sp/Dom_ violence.htm

Chang, H.J. (2010). Severe mental disorders in offspring with 2 psychiatrically ill parents. Journal of American Medical Association, 303(19), 1896.

Cleaver, H., Unell, I., \& Aldgate, J. (1999). Children's needsparenting capacity: The impact of parental mental illness, problem alcohol and drug use, and domestic violence on children's development. Norwich, UK: The Stationery Office.

Connell, A.M., \& Goodman, S.H. (2002). The association between psychopathology in fathers versus mothers and children's internalizing and externalising behavior problems: A meta-analysis. Psychological Bulletin, 128, 746-773.

Cooklin, A. (2006). Children of parents with mental illness. In L. Combrinck-Graham (Ed.), Children in family contexts: Perspectives on treatment (pp. 265-291). New York: Guilford Press.

Cousins, C. (2004). When is it serious enough? The protection of children of parents with a mental health problem, tough decisions and avoiding a 'martyred' child. Australian e-journal for the advancement of Mental Health, 3(2).

Cowling, V., Luk, E.S.L., Mileshkin, C., \& Birleson, P. (2004). Children of adults with severe mental illness: Mental health, help seeking and service use. Psychiatric Bulletin, 28(1), 43-46.

Cowling, V., Edan, V., Cuff, R., Armitage, P., \& Herszberg, D. (2006). Mental health consumer and carer participation in professional education. 'Getting there together' for children of parents with mental illness and their families. Australian Social Work, 59, 4, 406-421.

Craig, E.A. (2004). Parenting programs for women with mental illness who have young children: A review. Australian and New Zealand Journal of Psychiatry, 38, 923-928.

Curtis, D. (2008). Genetics of mental illness (Lecture Series). Retrieved November 8, 2010, from http://www.mds. qmw.ac.uk/statgen/dcurtis/lectures/

Darlington, Y., \& Feeney, J.A. (2009). Clients' and professionals' experiences of traversing mental health and child protection systems: Implications for practice. Families in Society, 90(4), 382. 
Davies, B., \& Allen, D. (2007). Integrating 'mental illness' and 'motherhood': The positive use of surveillance by health professionals. A qualitative study. International Journal of Nursing Studies, 44(3), 365.

De Bellis, M.D., Broussard, E.R., Herring, D.J., Wexler, S., Moritz, G., \& Benitez, J.G. (2001). Psychiatric co-morbidity in caregivers and children involved in maltreatment: A pilot research study with policy implications. Child Abuse and Neglect, 25, 923-944.

Department of Families, Housing, Community Services and Indigenous Affairs. (2010). Current status of women in Australia. Retrieved November 8, 2010, from http://www. fahcsia.gov.au/sa/women/pubs/general/equal_opp_review /Pages/p2.aspx

Devlin, J.M., \& O’Brien, L.M. (1999). Children of parents with mental illness. I: An overview from a nursing perspective, Australian and New Zealand Journal of Mental Health Nursing, 8(1): 19-29.

Dixon, L., Browne, K., \& Hamilton-Giachristsis, C. (2005). Risk factors of parents abused as children: A meditational analysis of the intergeneration continuity of child maltreatment (Part 1). Journal of Child Psychology and Psychiatry, 46(1), 47-57.

Ehrensaft, M.K., Moffitt, T.E., \& Capsi, A. (2006). Is domestic violence followed by an increase risk of mental illness? Psychiatry, 163, 885-892.

Ellsberg, M., Jansen, H., Heise Lori, A.F.M., Watts, C.H., \& Garcia-Moreno, C. (2008). Intimate partner violence and women's physical and mental health in the home and domestic violence: An observational study. The Lancet, 371, 1165-72.

Fraser, E., \& Pakenham, K.I. (2009). Resilience in children of parents with mental illness: Relations between mental health literacy, social connectedness and coping, and both adjustment and caregiving. Psychological Health and Medicine, 14(5), 573-84.

Fischbach, R.L., \& Herbert, B. (1997). Domestic violence and mental health: Correlates and conundrums within and across cultures, Social Science \& Medicine, 45(8), 11611176.

Foster, K. (2005, November). Disturbing the silences-on having a parent with mental illness. Keynote address presented to the 6th Collaborative Psychiatric Nursing Conference, Melbourne, Australia.

Fudge, E., \& Robinson, P. (2009). A public health approach to promoting better mental health outcomes for children of parents with a psychiatric disability. Psychiatric Rehabilitation Journal, 33(2), 83-90.

Furlong, M.A. (2001). Constraints on family sensitive mental-health practices. Journal of Family Studies, 7(2), 217-232.

Gilles, V. (2005). Meeting parents' needs? Discourses of "support" and "inclusion" in family policy. Critical Social Policy. 25(1), 70-90.

Golding, J.M. (1999). Intimate partner violence as a risk factor for mental disorders: A meta-analysis', Journal of Family Violence, 14(2), 99-132.
Grbich, C. (1999). Qualitative research in health: An introduction. St Leonards, Australia: Allen \& Unwin

Hetherington, R., Baistow, K., Katz, I., Mesie, J., \& Trowell, J. (2002). The welfare of children with mentally ill parents: Learning from inter-country comparisons. New York: John Wiley \& Sons.

Kai, J., \& Crosland, A. (2001). Perspectives of people with enduring mental ill health from a community-based qualitative study. British Journal of General Practice, 51(470), 730-736.

Kahng, S.K., Oyserman, D., Bybee, D., \& Mowbray, C. (2008). Mothers with serious mental illness: When symptoms decline does parenting improve? Journal of Family Psychology, 22(1), 162.

Kitzmann, K.M., Gaylord, N.K., Holt, A.R., \& Kenny, E.D. (2003). Child witnesses to domestic violence: A meta-analytic review. Journal of Consulting and Clinical Psychology, 71(2), 339-352.

Lawler, S. (2002). Narrative in social research. In T. May (Ed.), Qualitative research in action (pp. 242-258). London: Sage.

Lester, H., Tritter, J., \& Sorohan, H. (2005). Patients and health professionals' views on primary care for people with serious mental illness: Focus group study. British Medical Journal, 330, 1122.

Macy, R.J., Giattina, M.C., Parish, S.L., \& Crosby, C. (2010). Domestic violence and sexual assault services: Historical concerns and contemporary challenges. Journal of Interpersonal Violence, 25(1), 3-32.

Manning, C., \& Gregoire, A. (2009). Effects of parental mental illness on children. Psychiatry, 8(1), 7-9.

Manning, C., \& Gregoire, A. (2006). Effects of parental mental illness on children. Psychiatry, 5(1), 10-12.

Maybery, D., Ling, L., Szakacs, E., \& Reupert, A. (2005). Children of parents with a mental illness. Perspectives on need. Australian e-Journal for the Advancement of Mental Health, 4(2).

Maybery, D., \& Reupert, A. (2006). Workforce capacity to respond to children whose parents have a mental illness. Australian and New Zealand Journal of Psychiatry, 40(8), 657-664.

McCloskey, L.A., \& Bailey, J.A. (2000). The intergenerational transmission of risk for child sexual abuse. Journal of Interpersonal Violence, 15(10),1019-1035.

Mowbray, C.T., Oyserman, D., Bybee, D., MacFarlane, P., \& Rueda-Riedlf, A. (2001). Life circumstances of mothers with serious mental illnesses. Psychiatric Rehabilitation Journal, 25(2), 114-123.

Newman, L., \& Mares, S. (2007). Recent advances in the theories of and interventions with attachment disorders. Current Opinion in Psychiatry, 20(4), 343-348.

Nicholson, J., \& Denevey, W. (2009). Why not support(ed) parenting? Psychiatric Rehabilitation Journal, 33(2), 79-82.

Nicholson, J., Albert, K., Gershenson, B., Williams, V., \& Biebel, K. (2009). Family options for parents with mental illnesses: A developmental, mixed methods pilot study. Psychiatric Rehabilitation Journal, 33(2),106-114. 
Nicholson, J., Hinden, B., Biebel, K., Henry, A., \& Katz-Leavy, J. (2007). A qualitative study of programs for parents with serious mental illness and their children: Building practice-based evidence. Journal of Behavioral Health Services \& Research, 34(4), 395-413.

Nicholson, J., \& Biebel, K. (2002). Commentary on 'Community Mental Health Care for Women with Severe Mental Illness Who are Parents: The Tragedy of missed opportunities: What providers can do'. Community Mental Health Journal, 38(2), 167-172.

Oyserman, D., Mowbray, C.T., Allen-Meares, P., \& Firminger, K. (2000). Parenting among mothers with a serious mental illness. American Journal of Orthopsychiatry 70(3), 296-315.

Payne, G., \& Williams, M. (2005). Generalization in qualitative research. Sociology, 39, 295-314.

Pescosolido, B.A., \& Wright, E.R. (2004). The view from two worlds: The convergence of social network reports between mental health clients and their ties. Social Science \& Medicine, 58, 1795-1806.

Pettit, W., Olino, T.M., Roberts, Seeley, J.R., \& Lewinsohn, P.M. (2008). Influence of parental and grandparental major depressive disorder on behavior problems in early childhood: A three-generation study. Journal American Academy of Child and Adolescent Psychiatry, 47(1), 53-60.

Pretis, M., \& Dimova, A. (2008). Vulnerable children of mentally ill parents: Towards evidence-based support for improving resilience. Support for Learning, 23(3), 152.

Price-Robertson, R., Smart, D., \& Bromfield, L. (2010). Family is for life: Connections between childhood family experiences and wellbeing in early adulthood. Family Matters, 85, 7-17.

Ramchandani, P., \& Jones, D.P.H. (2003). Treating psychological symptoms in sexually abused children. . British Journal of Psychiatry, 183, 484-490.

Reid, J. (2005). Coming out of the dark: Children of parents with a mental illness. Every Child, 11(1), 14-15.

Repetti, R.L., Taylor, S.E., \& Seeman, T.S. (2002). Risky families: Family social environments and the mental and physical health of the offspring. Psychological Bulletin, 128, 330-366.

Reupert, A., \& Maybery, D. (2009). A 'snapshot' of Australian programs to support children and adolescents whose parents have a mental illness. Psychiatric Rehabilitation Journal, 33(2), 125-132.
Roberts, G.L., Williams, G.M., Lawrence, J.M., \& Raphael, B. (1998). How does domestic violence affect women's mental health? Women and Health, 28(1), 117-129.

Sartorius, N., \& Henderson, A.S. (1992). The neglect of prevention in psychiatry. Australian and New Zealand Journal of Psychiatry, 26, 550-553.

Silverman, D. (1993). Interpreting qualitative data: Methods for analysing talk, text and interaction. London: Sage.

Sirotich, F. (2008). Correlates of crime and violence among persons with mental disorder: An evidence-based review. Brief Treatment and Crisis Intervention, 8(2), 171-194.

Spataro, J., Mullen, P.E., Burgess, P.M., Wells, D.L., \& Moss, S.A. (2004). Impact of child sexual abuse on mental health: Prospective study in males and females. British Journal of Psychiatry, 184, 416-421.

Tandon, M., Cardeli, E., \& Luby, J. (2009). Internalizing disorders in early childhood: A review of depressive and anxiety disorders. Child and Adolescent Psychiatric Clinics of North America, 18(3), 593-610.

Taft, A. (2003). Promoting women's mental health: The challenges of intimate/domestic violence against women (Paper no. 8.) Sydney Australia: Australian Domestic and Family Violence Clearinghouse.

Taylor A., Toner P., Velleman R., \& Templeton, L. (2008). Parental alcohol misuse in complex families: The implications for engagement. British Journal of Social Work 38, 843-864.

Thomas, L., \& Kalucy, R. (2003). Parents with mental illness: Lacking motivation to parent. International. Journal of Mental Health Nursing, 12, 153-157.

Trocme, N., \& Wolfe, D. (2001). Child maltreatment in Canada: Selected results from the Canadian Incidence Study of reported Child Abuse and Neglect. Ottawa, ON: Minister of Public Works and Government Services.

Velleman, R., Reuber, D., Klein, M., Templeton, L., \& Moesgen, D. (2008). Domestic abuse experienced by young people living in families with alcohol problems: Results from a cross-European study. Child Abuse Review, 17, 387-409.

Wright, N., \& Owen, S. (2001). Feminist conceptualisations of women's madness: A review of the literature. Journal of Advanced Nursing, 36(1), 143-150. 